\section{Difference in Cell Proliferation and Spontaneous Mediator Release Between Two Mast Cell Lines, NCL-2 and RBL-2H3 on Honey Comb- like Structured Film}

\author{
Hyunmi Choi ${ }^{1,2}$, Masaru Tanaka ${ }^{2,3 *}$ and Koreaki Sugimoto ${ }^{1 *}$ \\ ${ }^{1}$ Department of Psychosomatic Neurology and Oral medicine, Tohoku \\ Fukushi University, Sendai, Japan
}

${ }^{2}$ Frontier Center for Organic Materials, Frontier Center for Organic Material Systems, Frontier Center for Organic System Innovations (MEXT COI), Soft Biomaterials Research Center, Tanaka Lab, Yamagata University, Yonezawa, Yamagata, Japan

${ }^{3}$ Institute for Materials Chemistry and Engineering, Kyushu University, Fukuoka 819-0395, Japan

\begin{abstract}
Mast cells are found in connective or mucosal tissues of the body, and play an important role in allergic reactions as well as the inflammatory and immune responses. Because mast cells produce and secrete a large number of mediators, as their functions and mechanisms are complex. Mast cells possess a unique feature of presenting diverse phenotypes that are dependent on the tissue microenvironments during their maturation in vivo. Therefore we advocate that non-tumor cells are more desirable than tumor cells such as Rat Basophilic Leukemia cells (RBL-2H3) and Human Mast Cells (HMC-1) for determining the changes in the character of mast cells in vivo. We previously reported a new non-tumor mast cell line, NCL-2, and described the morphological and proliferative changes occurring in mast cells growing on Honeycomb-like Films (HCF) using NCL-2 cells. In the present study, we compared the changes in the proliferation pattern and morphology between NCL-2 and $\mathrm{RBL}-2 \mathrm{H} 3$ cells as well as in the spontaneous release of histamine
\end{abstract}

*Corresponding authors: Koreaki Sugimoto, Department of Psychosomatic Neurology and Oral medicine, Tohoku Fukushi University, Sendai 989-3201, Japan, Tel: +81 222742239; Fax: +81 222742239; E-mail: k-s@umin.ac.jp; koreaki-s@jcom.home.ne.jp

Masaru Tanaka, Frontier Center for Organic Materials, Yamagata University, Yonezawa, Yamagata 992-8510, Japan, Tel: +81 928026235; Fax: +81 928026235; E-mail: tanaka@yz.yamagata-u.ac.jp

Citation: Choi H, Tanaka M, Sugimoto K (2016) Difference in Cell Proliferation and Spontaneous Mediator Release Between Two Mast Cell Lines, NCL-2 and RBL-2H3 on Honey Comb-like Structured Film. J Nanotechnol Nanomed Nanobiotechnol 3: 009.

Received: December 04, 2015; Accepted: January 25, 2016; Published: February 10, 2016 and Leukotriene B4 (LTB4) from these cells cultured on HCF as the surrounding micro environment. Compared with RBL-2H3 cells, which have been most frequently used for mast cell research, NCL-2 cells displayed increasing floating cells, multinuclear formation, and no changing of histamine release but decreasing LTB4 release, on the HCFs. Hence, we are convinced that HCF plays different roles as physical stimuli for the spontaneous release of histamine and LTB4 from NCL-2 and RBL-2H3 cells. HCF has huge potential for use in the new therapeutic treatment of allergy and inflammation by inhibiting the function of mast cells.

Keywords: Histamine; Honeycomb-like Film (HCF); Leukotriene B4 (LTB4); NCL-2 cells; RBL-2H3 cells

\section{Introduction}

Mast cells play an important role in allergic reactions as well as in the inflammatory and immune responses [1,2]. Mast cell self-protection during an immune response can lead to inflammatory diseases and allergic diseases owing to excessive reactions $[3,4]$. As mast cells are hematopoietic cells, unlike other blood cells, they migrate to the peripheral tissues as immature progenitors and differentiate into mature mast cells $[5,6]$. One of the unique features of mast cells includes demonstration of diverse phenotypes depending upon the tissue microenvironment during their maturation in vivo [7].

Cell lines for mast cell culture have been established from tumor cells including Rat Basophilic Leukemia cells (RBL-2H3) and Human Mast Cells (HMC-1). Although non-tumor mast cells can be differentiated from Bone Marrow-derived Mast Cells (BMMCs) precursors in vitro [8], these non-tumor mast cells cannot be maintained in culture as cell lines. But non-tumor cells seem more preferable for studying the alterations of the properties of mast cells in vivo. Therefore, we had studied the morphological and proliferation changes in mast cells using new autonomous proliferative non-tumor mast cells, NCL-2 cells, on Honeycomb-like Film (HCF) [9].

In recent years, several studies have reported the behaviors of cells on biomaterials [10-12]. For example, cell proliferation, adhesion and morphological changes have been reported to be affected by different materials [13-15]. It is also possible to produce a physical microenvironment based on the design shape, mechanical properties, and surface topology of biomaterials [16-19]. Mitragotri et al., reported that the narrow specifications of elastic moduli create mechanically defined microenvironments that effectively support the development of cellular architecture [20].

The research on inflammatory and immune responses or allergic reactions has advanced in studies involving mast cells. However, studies on the morphological and functional changes in mast cells influenced by the microenvironment or the surrounding circumstances are limited.

Among the mediators secreted by mast cells, histamine is secreted via degranulation through exocytosis during allergic and anaphylactic responses, whereas specific mediators are secreted through differential release without degranulation in inflammatory diseases $[21,22]$. For instance, biogenic amines (e.g., histamine), chemokines, enzymes (e.g., chymase and tryptase), peptides (e.g., corticotrophin-releasing 
factor and Substance P [SP]), and proteoglycans (e.g., chondroitin sulfate and heparin) are produced and stored in mast cells and released via degranulation. In contrast, cytokines (e.g., Tumor Necrosis Factor [TNF]- $\alpha$ ) and arachidonic acid products (e.g., Leukotriene B4 [LTB4]) are synthesized de novo and then released [22].

Mast cells are distributed differentially in different organs such as nose, lung, digestive tract, and brain with different densities. Based on characteristics of the body parts where the mast cells are localized, these cells may alter the secretory pathway or the types of mediators employed [23]. Because two types of mediators, i.e., preformed mediators (e.g., histamine, heparin, serotonin, and SP) and de novo-synthesized mediators (e.g., TNF- $\boldsymbol{\alpha}$, LTB4, and interleukin), are released upon the activation of mast cells [24], we speculated that mast cells are stimulated not only by chemicals and antigen but also by the physical environment in vivo.

In this study, therefore, to find the property of non-tumor mast cells stimulated by extracellular physical microenvironment, we examined the different type of mast cells, NCL-2 and RBL-2H3 cells, that were cultured on HCF with different-sized pores as the culture substrates. This report presents, for the first time, the changes in the spontaneous release of mediators (i.e., histamine, LTB4) and the resultant morphology of both of the cell types.

\section{Materials and Methods}

\section{Preparation of HCF}

Porous HCFs composed of polystyrene were fabricated using water droplets as templates for regular pores. Briefly, polystyrene, didecyl acrylamide, and $\omega$-carboxyhexylacrylamide (CAP) (10:1\%wt) were dissolved in chloroform at a concentration of $5 \mathrm{~g} / \mathrm{L}$, and the polymer mix was layered onto glass cover slips in a humid environment. The pore sizes were regulated by changing the casting conditions (i.e., temperature, humidity, gas flow rate, casting volume, and casting concentration) of the polymer solution $[14,25]$. Three pore sizes of $3,5,10 \mu \mathrm{m}$-HCF were fabricated and used in this experiment.

\section{Cell lines}

RBL-2H3 cells are a basophilic leukemia cell line derived from the peripheral blood of rats. These cells were provided by Tohoku University.

NCL-2 cells are non-tumor cells derived from the bone marrow of NC [Cinnamon (C) coat-colored Nishiki (N)] mice, which are used as a model for atopic dermatitis. These cells, which were isolated by Hide et al., at the Hiroshima University, Japan, in 2006, can proliferate autonomously without self-phosphorylation of c-kit receptors $[9,26,27]$. NCL-2 cells express high-affinity IgE receptors (FceRI) and release histamine, $\beta$-hexosaminidase, triptase, interleukin- 6 , TNF- $\alpha$, and LTB4 through stimulation of FceRI or other stimuli [27]. NCL-2 cells maintain the characteristics of mucosal mast cells carried from the bone marrow mast cells of NC mice, such as showing positive Alcian blue staining, negative safranin staining, decreased histamine levels, and no response to SP [27].

\section{Cell culture}

RBL-2H3 and NCL-2 cells were cultured in Minimum Essential Medium a (MEMa; Gibco, USA) supplemented with 10\% Fetal Calf Serum (FCS; Thermo, Japan), $2 \mathrm{mM}$ glutamine, $100 \mathrm{IU} / \mathrm{mL}$ penicillin $\mathrm{G}$, and $100 \mathrm{mg} / \mathrm{ml}$ streptomycin (complete MEMa), as well as $50 \mu \mathrm{M}$ 2-mercaptoethanol for NCL-2 cells only.
These cells were maintained at $37^{\circ} \mathrm{C}$ in a $5 \% \mathrm{CO}_{2}$-containing atmosphere. Polystyrene film rounds (15 $\mathrm{mm}$ diameter) were set in 24 -well plates and sterilized with $99.5 \%$ alcohol. The films were either flat (without a honeycomb-like structure) or porous with a pore size of 3,5 , or $10 \mu \mathrm{m}$. The cells were cultured on these round films in 24-well plates.

\section{Measurement of cell numbers}

Cells were seeded at a density of $1 \times 10^{5}$ cells $/ \mathrm{mL}$, and incubated for 1 week on glass cover slips and polystyrene films (flat films or 3,5 , or $10 \mu \mathrm{m}$ pore-sized $\mathrm{HCF}$ ), following which the growth rates of the adherent and suspended cells were quantified.

One week after seeding, the cells in the suspensions were collected in all suspensions and counted using a hemocytometer and a phase-contrast microscope $(n=4)$. Next the number of adherent cells on each HCFs was counted ten times at five random points (NCL-2 cell: $0.32 \times 0.32 \mathrm{~mm}^{2}$ area, RBL-2H3 cell: $0.316 \times 0.316 \mathrm{~mm}^{2}$ area, respectively) on one sheet under a Confocal Laser-scanning Microscopy (CLSM; $n=2$ ) [9]. Lustrous round cells in the suspensions and DAPI stained clear cells adhered on the films were recognized alive and counted manually through a phase-contrast microscope and a CLSM, respectively.

\section{Confocal laser-scanning microscopy observations}

To observe the morphology and adhesive state of the cells, cells cultured on films for 1 week were subjected to immunofluorescence staining. These cells were washed with PBS and then fixed in $4 \%$ paraformaldehyde-PBS (Wako Pure Chemical Industries, Ltd., Japan) for $10 \mathrm{~min}$ at $37^{\circ} \mathrm{C}$. The cells were subsequently washed with PBS for 10 min and permeabilized through three 10 min washes with $1 \%$ Triton X-100 (MP Biomedicals, LLC, USA) in PBS. After three $10 \mathrm{~min}$ washes with $0.02 \%$ Tween 20 in PBS, the cells were stained for $1 \mathrm{hr}$ with a mouse anti-vinculin monoclonal antibody (1/100 dilution; Millipore, Temecula, USA) at $37^{\circ} \mathrm{C}$. The stained cells were then rinsed three times with $0.02 \%$ Tween 20 in PBS for 10 min each. Next, in a dark room, the cells were stained for $1 \mathrm{~h}$ with an Alexa Fluor 546-labeled goat anti-mouse IgG antibody (1/1000 dilution; Molecular Probes, USA) and Alexa Fluor 488-labeled phalloidin (1/1000 dilution; Molecular Probes, USA) at $37^{\circ} \mathrm{C}$. After three 10 min washes with $0.02 \%$ Tween 20 in PBS, all samples were transferred to slides with a prolonged gold antifade reagent and 4,6-Diamidino-2-Phenylindole (DAPI; Molecular Probes, USA), and glass cover slips were applied and sealed with fingernail polish. The excitation wavelength of the CLSM (Olympus FV1000; Japan) was set to $488 \mathrm{~nm}$, and a 546 or $568 \mathrm{~nm}$ filter was used to collect the emitted light. Images were acquired by using FV10-ASW software, version 1.7.

The CLSM observations showed the anti-vinculin antibody, phalloidin, and DAPI stains representing focal adhesion molecules (red), F-actin (green), and nuclei (blue), respectively.

\section{Scanning Electron Microscopy (SEM) observations of NCL-2 and RBL-2H3 cells}

After NCL-2 and RBL-2H3 cells were cultured for 1 week, the suspended cells on the each film were subsequently fixed in $1 \%$ glutaraldehyde in Phosphate-buffered Saline (PBS) (MP Biomedicals, LLC.) overnight at $4^{\circ} \mathrm{C}$. Then, the cells were rinsed in PBS for $10 \mathrm{~min}$. Subsequently, the sample was dehydrated in a graded ethanol series and air-dried. The dried samples were mounted on aluminum stages with tape and coated with palladium gold using an ion sputter coater 

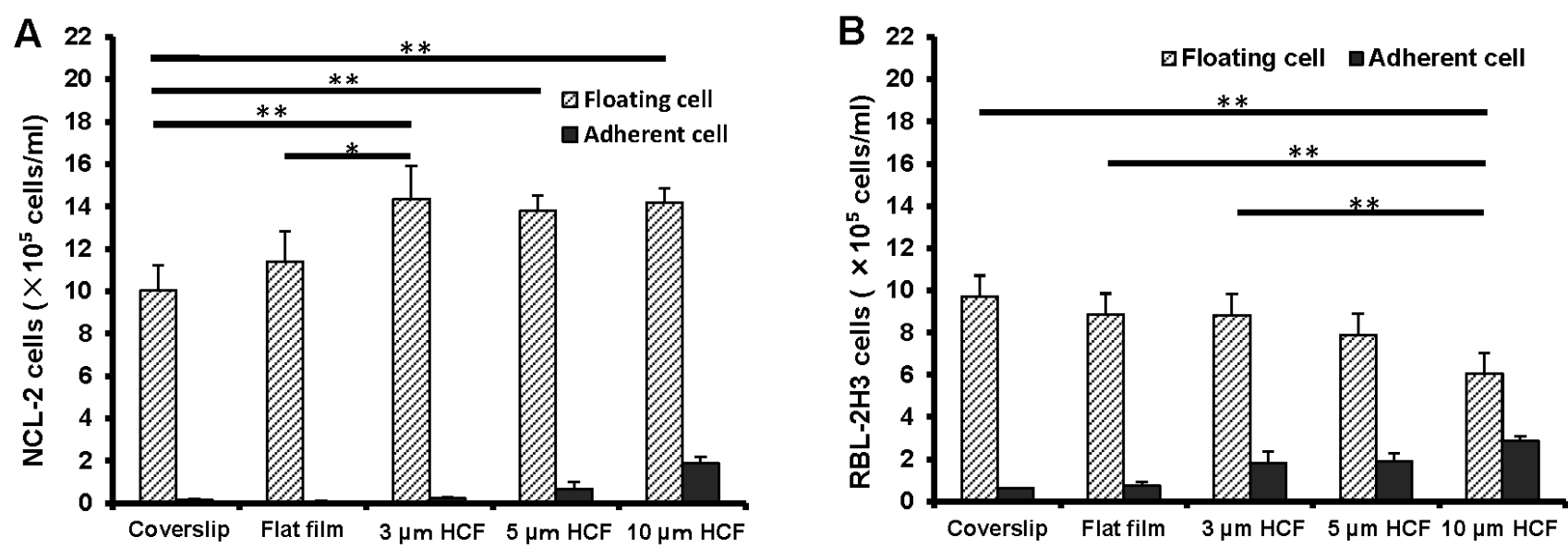

Figure 1: As a result, the number of floating NCL-2 cells significantly increased, whereas that of RBL-2H3 cells significantly decreased on the HCFs. On the other hands, both the number of adherent cells increased gradually on the polystyrene films, prefer HCFs to flat film. This result reveals that the proliferation properties of these mast cell lines are different. One of the reason those above is that NCL-2 cells have floating property, and RBL-2H3 cells have adhesive property, respectively.

(JEOL, JFC-1200 fine coater). All samples $(\mathrm{n}=4)$ were observed by SEM (Hitachi SU 8000).

\section{Measurement of spontaneous histamine release}

After 1 week of culture, the cells were suspended and centrifuged at $1400 \mathrm{~g}$ (3,000 rpm) for $3 \mathrm{~min}$. The histamine spontaneously released into the cell supernatant was measured by using an Enzyme Immunoassay (EIA) kit (A05890-96 wells; SPI-BIO; Bertin Pharma, USA). This EIA kit functions on the principle of competition between unlabeled, derivatized histamine and Acetylcholinesterase (AChE) linked to histamine (tracer) for a limited number of specific mouse anti-histamine antibody sites. The absorbance was read at $405 \mathrm{~nm}$ on a micro plate absorbance spectrophotometer (Bio-RAD, USA).

\section{Measurement of spontaneous LTB4 release}

We measured the LTB4 that was spontaneously released into the cell supernatant by using an EIA kit (ADI-900-068; Enzo Life Sciences, USA). This EIA kit employs a polyclonal antibody against LTB4 to competitively bind either the LTB4 in the sample or an alkaline phosphatase molecule covalently attached to LTB4. After

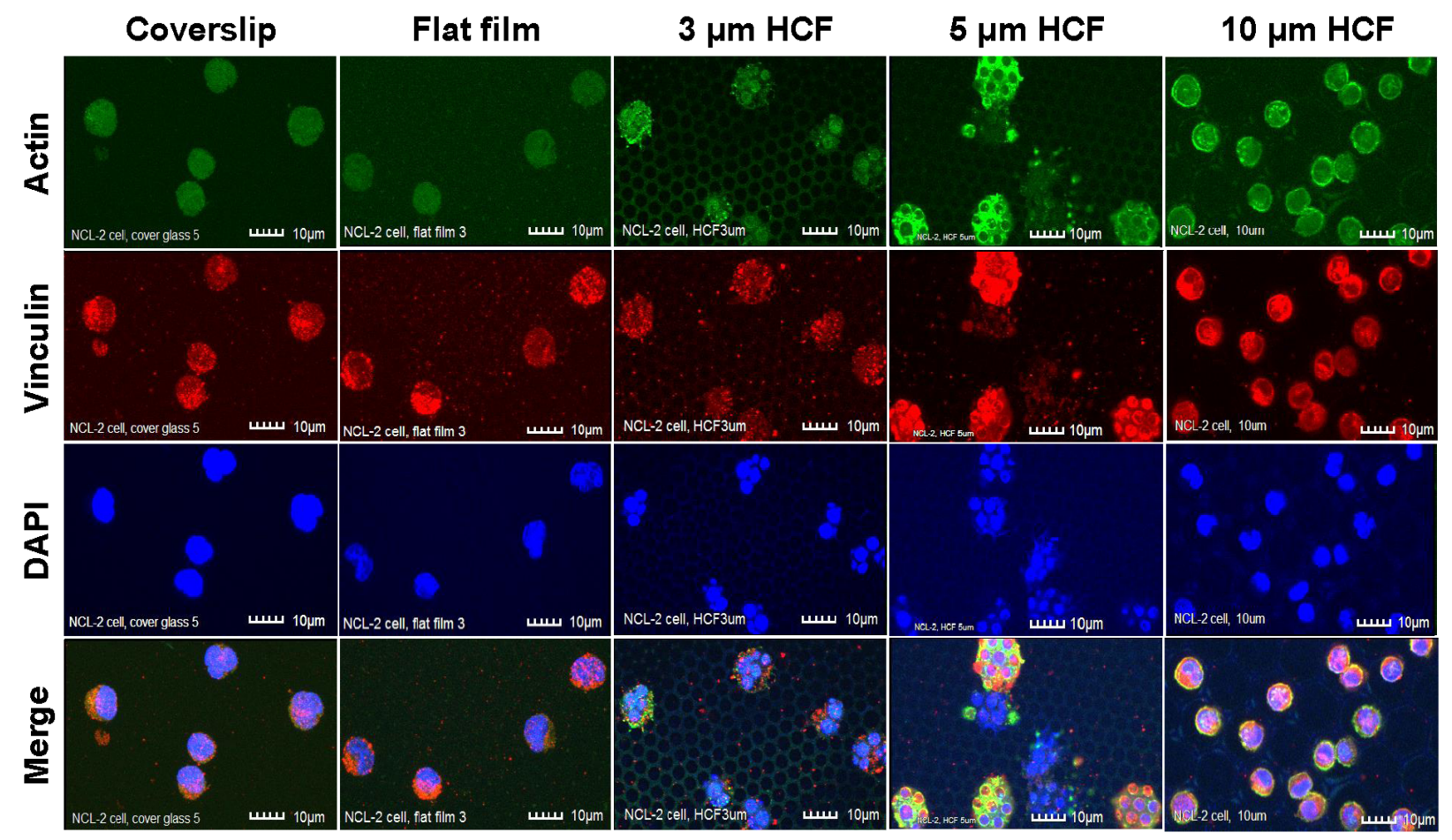

Figure 2: The CLSM images of NCL-2 cells stained immunofluorescently for actin, vinculin, and DAPI (nuclei) on glass cover slips, flat films, and on 3,5 , or $10 \mu \mathrm{m}$ HCF. The CLSM images for actin, vinculin, and DAPI are represented in green, red, and blue, respectively. Many NCL-2 cells were observed as spherical cells on every film, and multinuclear formation was observed on the only 3 and $5 \mu \mathrm{m} \mathrm{HCF}$. Scale bars $=10 \mu \mathrm{m}$. 


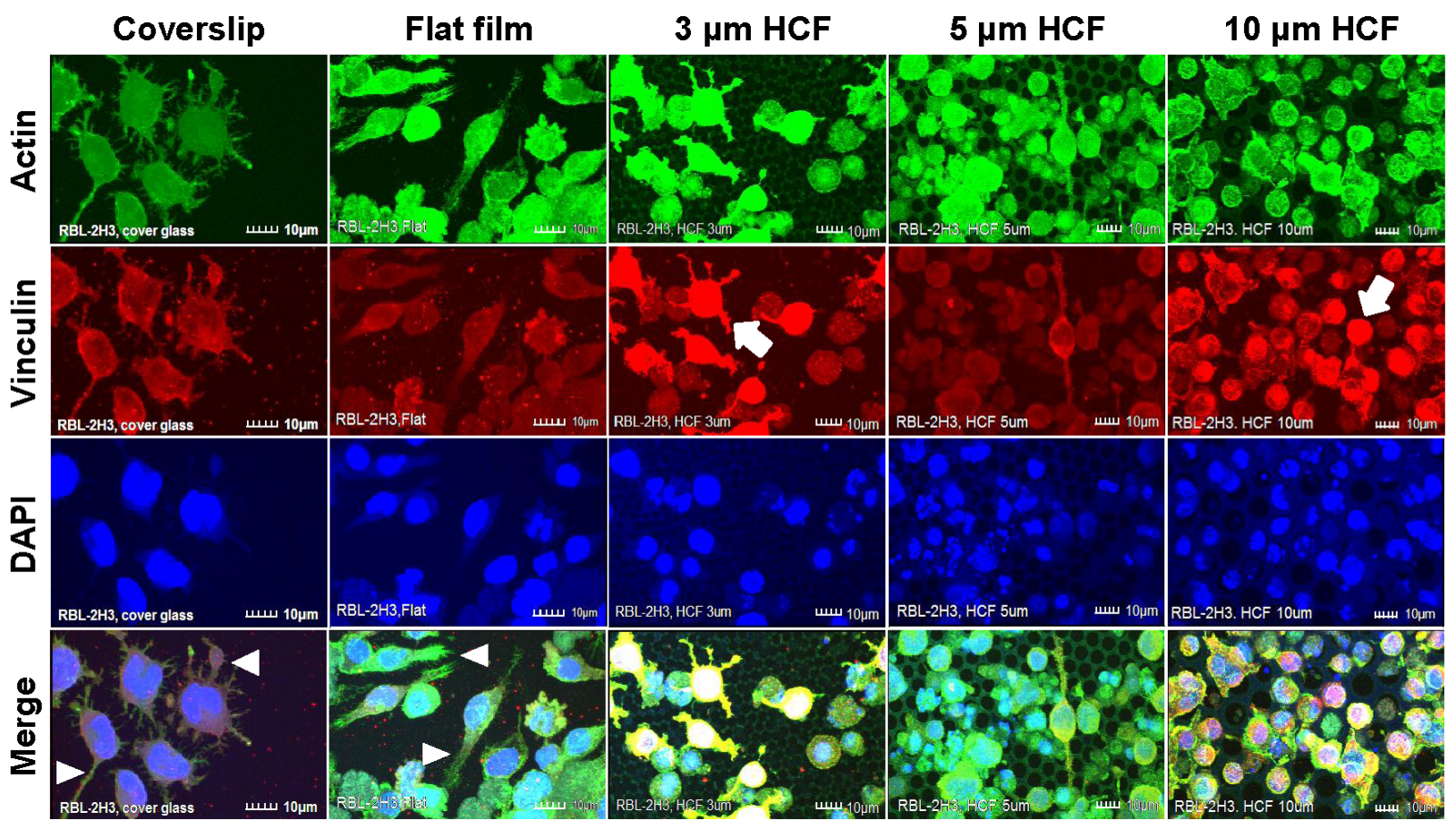

Figure 3: The CLSM images of RBL-2H3 cells stained immunofluorescently for actin, vinculin, and DAPI (nuclei) on glass cover slips, flat films, and 3 , 5 , or $10 \mu \mathrm{m}$ HCF. The CLSM images show for actin, vinculin, and DAPI are represented in green, red, and blue, respectively. Many RBL-2H3 cells were found to display adherent pseudopodia (white arrowhead) on cover slip and flat films. Stronger expression of vinculin (white arrow) was observed on cells attached to HCFs in comparison with cells adhering to the flat glass cover slip and flat film. Scale bars $=10 \mu \mathrm{m}$.

incubation at room temperature, the excess reagents were washed off, the substrate was added, and incubated for $2 \mathrm{hr}$, following which the enzyme reaction was stopped and the absorbance was read at $405 \mathrm{~nm}$ on the micro plate absorbance spectrophotometer.

\section{Statistical analysis}

Data were expressed as the mean \pm Standard Deviation (SD), as indicated in the figure legends. Multiple groups were analyzed by one-way Analysis of Variance (ANOVA) followed by Tukey's test for parametric data. Values of ${ }^{*} \mathrm{p}<0.05$ and ${ }^{* *} \mathrm{p}<0.01$ were considered significant.

\section{Results}

\section{Proliferation on flat film and HCF of different pore sizes}

In this experiment, physical stimulation was provided by using an extracellular matrix for mast cells rather than by using a chemical stimulus such as DNP-HAS, $\mathrm{HgCl}_{2}$, or $\mathrm{Ca}^{2+}$ ionophores [28,29]. Using this method, we investigated the properties of two types of mast cells, NCL-2 and RBL-2H3, in different microenvironments in vitro.

Examination of the proliferation of endothelial cells on HCF of different pore sizes revealed that the increase in the number of adherent cells was high on an HCF with a pore size of $5 \mu \mathrm{m}$ [14]. Therefore, we designed the experimental protocol for pore sizes 3 and $10 \mu \mathrm{m}$, in addition to that of $5 \mu \mathrm{m}$.

The number of floating NCL-2 cells on the polystyrene films was more than that on the glass cover slips, further even on the same polystyrene films, the number of floating NCL-2 cells on HCFs were more than that on flat film (Figure 1A). Whereas, the number of floating RBL-2H3 cells on the polystyrene films gradually decreased in comparison with that on glass cover slips, with significant reduction on the $10 \mu \mathrm{m}$ HCF (Figure 1B). However, both numbers of adherent NCL-2 and RBL-2H3 cells gradually increased on the polystyrene films as compared with those on the glass cover slips, with the greatest increase on $10 \mu \mathrm{m} \mathrm{HCF} \mathrm{(Figures} \mathrm{1A} \mathrm{and} \mathrm{B).} \mathrm{The} \mathrm{number}$ of adherent RBL-2H3 cells was higher than that of adherent NCL-2 cells.

\section{CLSM observations of adhered cells on the culture substrate}

Due to the adherence of the cells to the culture substrate, under CLSM, the NCL- 2 cells on the 3 and $5 \mu \mathrm{m}$ HCF were multinucleated and appeared slightly larger than the cells adhered onto the glass cover slips and the flat films (Figure 2). This finding suggests that NCL-2 cells can extend along the structure of films with pores [9].

RBL-2H3 cells that adhered to the glass cover slips and flat films revealed many pseudopodia formation. However, on the HCFs, the adhering RBL-2H3 cells formed fewer pseudopodia, and most of the RBL-2H3 cells on the HCF were spherical and did not exhibit multinuclear formation. Whereas stronger expression of vinculin on each HCF were observed on RBL-2H3 cells in close attaching each other, compared with that on flat glass cover slip and flat film (Figure 3).

Greater numbers of adhering NCL-2 and RBL-2H3 cells were observed on the $10 \mu \mathrm{m}$ HCF (Figures 2 and 3). In addition, greater number of small cells from both the cell lines entered into the pores of the $10 \mu \mathrm{m}$ HCF than that adhered onto the films. Because the sizes of the mast cells are almost less than $10 \mu \mathrm{m}$, these small cells were assumed to be spherical shape into the $10 \mu \mathrm{m}$ pore size of HCF. 

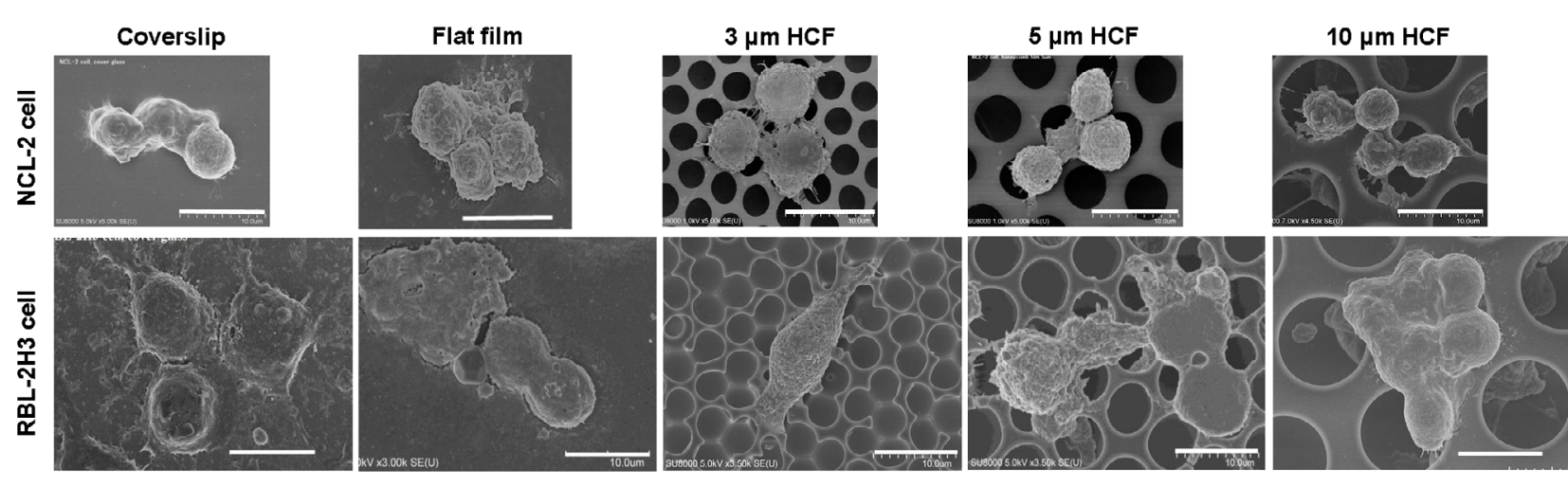

Figure 4: SEM images of NCL-2 and RBL-2H3 cells on glass cover slips, flat films, and 3, 5, or $10 \mu \mathrm{m}$ HCF. Scale bars=10 $\mu \mathrm{m}$.

As a result, CLSM revealed that the adherent NCL-2 cells demonstrate an altered morphology (multinuclear formation) based on the pore sizes of the HCF. However, these cells were not influenced by the different materials (between flat glass cover slip and flat polystyrene film). Whereas the adhesive RBL-2H3 cells showed morphological changes to pseudopodia formation or spherical shape depending on flat or honeycomb like structure. These findings demonstrated that the morphological properties of the each mast cell line are influenced by the differences on the extracellular substrates and structures.

\section{SEM observations of adhered cells on the culture substrate}

Figure 4, shows SEM images of 1 week culture of NCL-2 and RBL-2H3 cells on the each film. Smaller NCL-2 cells cultured on 10 $\mu \mathrm{m}$ HCF entered into the HCFs. Some RBL-2H3 cells attached to the 3 and $5 \mu \mathrm{m} \mathrm{HCF}$ with growing pseudopodia along the rims of holes.
The concentration of histamine released from RBL-2H3 cells was the same on the glass cover slips and flat films. However, this concentration gradually increased with the increase in the pore sizes of the HCF (Figure 5B). Although the films with flat and honeycomb-like structures were composed of the same polystyrene, the concentration of histamine on the HCF increased $137 \%$ to $305 \%$ in comparison with that observed on flat films without pores.

As a result, the spontaneous release of histamine from NCL-2 cells was not altered by the difference in the material or structure of the substrate. However, the release of histamine from RBL-2H3 cells on HCF was influenced gradually by the honeycomb-like structure, despite using the same material (polystyrene) as a substrate.

\section{Measurement of spontaneous LTB4 release}

The concentration of LTB4 spontaneously released from NCL-2 cells into the cell suspension was somewhat higher on the flat films
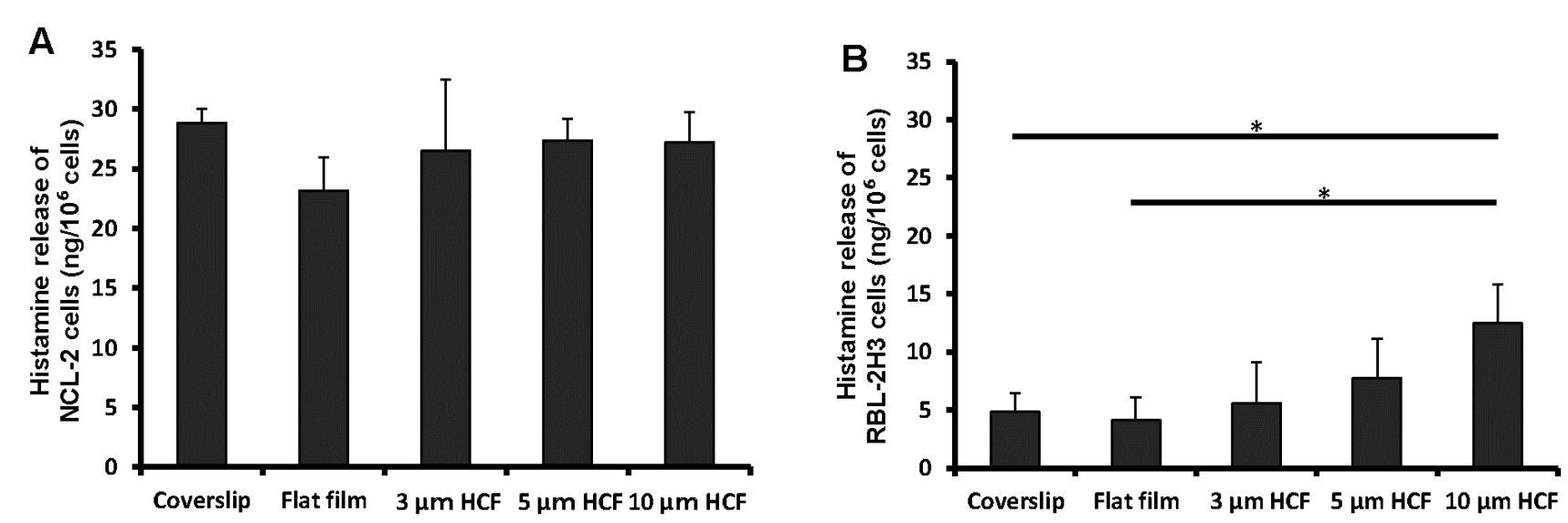

Figure 5: A comparison of spontaneous histamine released by NCL-2 and RBL-2H3 cells. The concentrations of histamine was measured in the supernatants after incubation for 1 week on the culture substrate $(n=4)$. A: NCL-2 cells, B: RBL-2H3 cells. The data are expressed as the mean \pm SD.

\section{Measurement of spontaneous histamine release}

Owing to its property as an important mediator in the allergic reaction and inflammatory responses, histamine is used as an indicator in the functional analysis of mast cells. The observed differences in the concentrations of histamine spontaneously released from NCL-2 cells were not significant into the cell suspensions of different materials (glass or polystyrene) or structures (flat or honeycomb-like structures) of culture substrates (Figure 5A). than on the glass cover slips; however, this concentration tends to reduced on HCFs with pores. The concentration of LTB4 released from NCL- 2 cells was reduced to $63 \%$ on the 3 and $5 \mu \mathrm{m}$ HCFs and to $57 \%$ on the $10 \mu \mathrm{m} \mathrm{HCF}$ relative to that on the flat film (Figure $6 \mathrm{~A}$ ). However, the concentration of LTB4 released from RBL-2H3 cells was not significantly different among the tested films (Figure 6B). The spontaneous release of LTB4 from NCL-2 cells was influenced by the difference in the material structure, while the spontaneous release of LTB4 from RBL-2H3 cells was influenced by the difference of neither material substrate nor structure. 

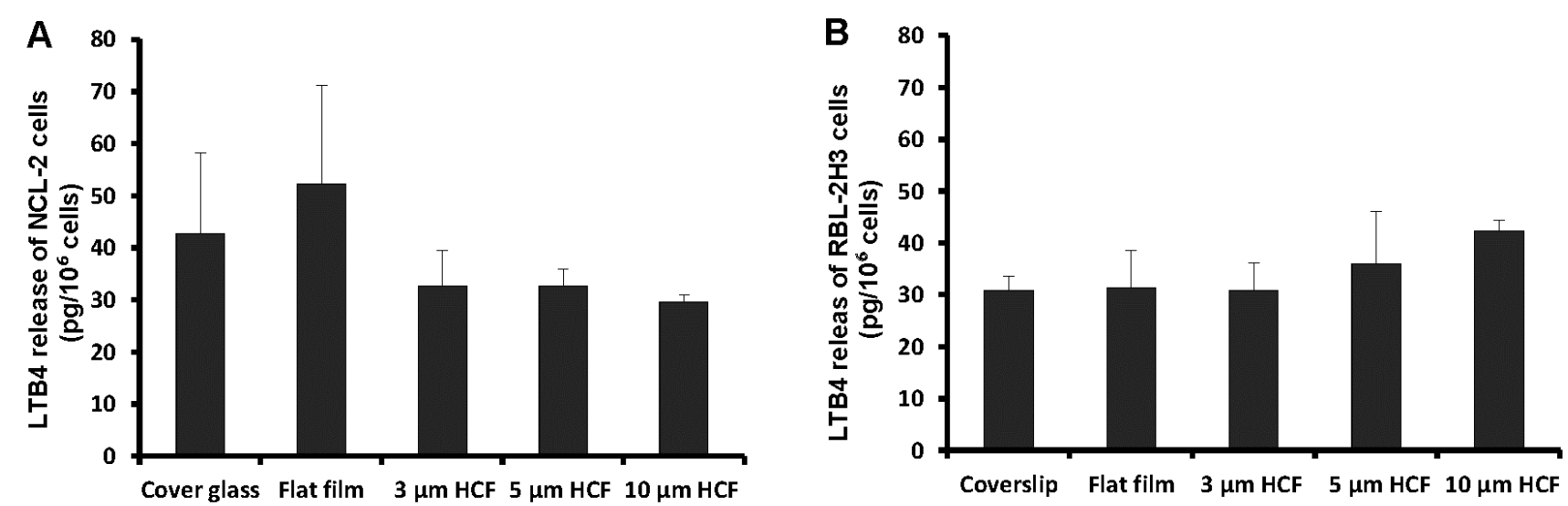

Figure 6: A comparison of spontaneous Leukotriene B4 (LTB4) released from NCL-2 and RBL-2H3 cells. The concentrations of LTB4 was measured in the supernatants after incubation for 1 week on the culture substrate $(n=4)$. A: NCL-2 cells, B: RBL-2H3 cells. The data are expressed as the mean \pm SD.

\section{Discussion}

To investigate the functional differences in these cell lines, we measured the spontaneous release of histamine and LTB4 from the NCL-2 and RBL-2H3 cells. Histamine is a pre-formed, stored mediator in mast cells, whereas LTB4 is a mediator synthesized de novo upon stimulation $[1,22]$. Histamine is the predominant, granule-associated mediator of acute reactions to mast cell activation. However, when mast cells are not activated, histamine is sequestered in mast cell granules by proteoglycans, such as heparin and chondroitin E [30]. While LTB4, a bioactive eicosanoid, is generated and released almost simultaneously along with granule-associated mediators through the receptor-mediated activation of Phospholipase (PL) A2 [30].

We previously reported that HCF selectively down-regulated the release of TNF- $\alpha$, LTB- 4 , and (to a lesser extent) SP, but not histamine. Attachment to HCF might have a greater effect on TNF- $\alpha$ and LTB-4 release because these molecules are synthesized de novo, whereas histamine and SP are pre-formed and stored in granules [31].

Our findings in this study suggest that pre-stored, granule-associated mediators and de novo-synthesized mediators possess different release patterns between these two types of mast cell lines and that they are stimulated by the extracellular matrix, i.e., by the different culture substrates and structures. This distinctive feature of release mediators may be concerned with cell-property. Cell proliferation on flat film and HCF of different pore sizes, and morphological change of adhered cells on the HCF, were quite different between two mast cell lines although they are mimic in vivo mast cells.

We are convinced that HCF plays different roles as physical stimuli for the spontaneous release of histamine and LTB4 from NCL-2 and RBL-2H3 cells.

Engler et al., [32] studied matrix stiffness and reported that mesenchymal stem cells showed strikingly different morphologies when cultured on polyacrylamide substrates with varying elasticities [32]. Thus, different materials, structures, surface topologies, and hardness's constitute the physical factors in culture substrates that influence cells $[33,34]$. In addition, when cells adhere to the culture substrate, cell information is transferred through integrins $[17,35,36]$. In particular, Focal Adhesion Kinase (FAK) transmits integrin- and/or receptor-dependent signals, leading to the control of cell motility, adherence, proliferation, and the prevention of cell from activating the apoptotic process [35]. In our study also; vinculin was expressed highly on the RBL- $2 \mathrm{H} 3$ cells that attached to other cells on HCFs.

Concerning the adhesion between the HCFs and mast cells, we speculated that special proteins such as FAK may be involved in the transfer of information. Therefore, we suggest that proteins are expressed specifically on mast cells due to their adhesion to the HCFs.

\section{Conclusion}

Because NCL-2 cells are non-tumor mast cells, we recommend the use of this cell line for mast cell research. Compared with RBL-2H3 cells which are the most frequently used for mast cell research, NCL-2 cells displayed the differences in the mode of floating cell proliferation, morphological alterations, and the release of histamine and LTB4 on various size of HCFs. Differences in the materials and pore sizes of HCF can affect these phenomena. We believe that understanding the changes in the function and morphology of NCL-2 cells influenced by HCF is critical because HCF has potential for use as a new therapeutic treatment method for allergy and inflammation.

\section{Acknowledgements}

The authors thank the Department of Dermatology, Hiroshima University for providing NCL-2 cells and the Institute of Development, Aging, and Cancer of Tohoku University for providing RBL-2H3 cells.

This work was supported by JSPSKAKENHI (Grant Number 22592099) and Next Generation World-Leading Researchers (NEXT Program Number LS017) in Japan.

\section{Conflict of Interests}

The authors declare no competing financial interests

\section{References}

1. Theoharides TC (2002) Mast cells and stress--a psychoneuroimmunological perspective. J Clin Psychopharmacol 22: 103-108.

2. Maurer M, Theoharides T, Granstein RD, Bischoff SC, Bienenstock J, et al (2003) What is the physiological function of mast cells? Exp Dermatol 12: $886-910$.

3. Galli SJ, Borregaard N, Wynn TA (2011) Phenotypic and functional plasticity of cells of innate immunity: macrophages, mast cells and neutrophils. Nat Immunol 12: 1035-1044. 
4. Amin K (2012) The role of mast cells in allergic inflammation. Respir Med 106: 9-14.

5. Silveira E Souza AM, Mazucato VM, Jamur MC, Oliver C (2011) Lipid rafts in mast cell biology. J Lipids 752906.

6. Frenzel L, Hermine O (2013) Mast cells and inflammation. Joint Bone Spine 80: 141-145.

7. Theoharides TC, Conti P (2004) Mast cells: the Jekyll and Hyde of tumor growth. Trends Immunol 25: 235-241.

8. Takano H, Nakazawa S, Okuno Y, Shirata N, Tsuchiya S, et al. (2008) Establishment of the culture model system that reflects the process of terminal differentiation of connective tissue-type mast cells. FEBS Lett 582: 1444-1450.

9. Choi H, Tanaka M, Hiragun T, Hide M, Sugimoto K (2014) Non-tumor mast cells cultured in vitro on a honeycomb-like structured film proliferate with multinucleated formation. Nanomedicine 10: 313-319.

10. Hallab NJ, Bundy KJ, O'Connor K, Moses RL, Jacobs JJ (2001) Evaluation of metallic and polymeric biomaterial surface energy and surface roughness characteristics for directed cell adhesion. Tissue Eng 7: 55-71.

11. Meyer U, Büchter A, Wiesmann HP, Joos U, Jones DB (2005) Basic reactions of osteoblasts on structured material surfaces. Eur Cell Mater 9: 39-49.

12. Morelli C, Barbanti-Brodano G, Ciannilli A, Campioni K, Boriani S, et al. (2007) Cell morphology, markers, spreading, and proliferation on orthopaedic biomaterials. An innovative cellular model for the "in vitro" study. J Biomed Mater Res A 83: 178-183.

13. Crespin M, Moreau N, Masereel B, Feron O, Gallez B, et al. (2011) Surface properties and cell adhesion onto allylamine-plasma and amine-plasma coated glass cover slips. J Mater Sci Mater Med 22: 671-682.

14. Tanaka M, Takayama A, Ito E, Sunami H, Yamamoto S, et al. (2007) Effect of pore size of self-organized honeycomb-patterned polymer films on spreading, focal adhesion, proliferation, and function of endothelial cells. J Nanosci Nanotechnol 7: 763-772.

15. Yang CY, Huang LY, Shen TL, Yeh JA (2010) Cell adhesion, morphology and biochemistry on nano-topographic oxidized silicon surfaces. Eur Cell Mater 20: $415-430$

16. Tanaka M, Nishikawa K, Okubo H, Kamachi H, Kawai T, et al. (2006) Control of hepatocyte adhesion and function on self-organized honeycomb-patterned polymer film. Physicochem Colloids Surf A 284-285: 464-469.

17. Yamamoto S, Tanaka M, Sunami H, Ito E, Yamashita S, et al. (2007) Effect of honeycomb-patterned surface topography on the adhesion and signal transduction of porcine aortic endothelial cells. Langmuir 23: 8114-8120.

18. Davidson PM, Özçelik H, Hasirci V, Reiter G, Anselme K (2009) Microstructured surfaces cause severe but non-detrimental deformation of the cell nucleus. Adv Mater 21: 3586-3590.

19. Ravichandran R, Liao S, Ng CCh, Chan CK, Raghunath M, et al. (2009) Effects of nanotopography on stem cell phenotypes. World J Stem Cells 1: 5566 .
20. Mitragotri S, Lahann J (2009) Physical approaches to biomaterial design. Nat Mater 8: 15-23.

21. Theoharides TC, Kempuraj D, Tagen M, Conti P, Kalogeromitros D (2007) Differential release of mast cell mediators and the pathogenesis of inflammation. Immunol Rev 217: 65-78.

22. Theoharides TC, Alysandratos KD, Angelidou A, Delivanis DA, Sismanopoulos N, et al. (2012) Mast cells and inflammation. Biochim Biophys Acta 1822: 21-33

23. Arck PC, Slominski A, Theoharides TC, Peters EM, Paus R (2006) Neuroimmunology of stress: skin takes center stage. J Invest Dermatol 126: 16971704.

24. Robbie-Ryan M, Brown M (2002) The role of mast cells in allergy and autoimmunity. Curr Opin Immunol 14: 728-733.

25. Fukuhira Y, Kitazono E, Hayashi T, Kaneko H, Tanaka M, et al. (2006) Biodegradable honeycomb-patterned film composed of poly (lactic acid) and dioleoylphosphatidylethanolamine. Biomaterials 27: 1797-1802.

26. Hide M, Okabe T, Hiragun T (2006) New mast cell strain and method using the same strain. Japanese patent (J-STOTE). Patent code P06A009473.

27. Hiragun T, Yanase Y, Okabe T, Hiragun M, Kawai M, et al. (2014) Establishment of a mast cell line, NCL-2, without Kit mutation, derived from NC mouse bone marrow. FEBS Open Bio 4: 342-346.

28. Urb M, Pouliot P, Gravelat FN, Olivier M, Sheppard DC (2009) Aspergillus fumigatus induces immunoglobulin E-independent mast cell degranulation. J Infect Dis 200: 464-472.

29. Kempuraj D, Asadi S, Zhang B, Manola A, Hogan J, et al. (2010) Mercury induces inflammatory mediator release from human mast cells. J Neuroinflammation 7: 20 .

30. Gilfillan AM, Beaven MA (2011) Regulation of mast cell responses in health and disease. Crit Rev Immunol 31: 475-529.

31. Sugimoto K, Choi H, Tanaka M (2014) Honeycomb-like structured film regulates mediator release from non-tumor mast cells. Eur J Inflamm 12: 515-520.

32. Engler AJ, Sen S, Sweeney HL, Discher DE (2006) Matrix elasticity directs stem cell lineage specification. Cell 126: 677-689.

33. Chen CS, Mrksich M, Huang S, Whitesides GM, Ingber DE (1997) Geometric control of cell life and death. Science 276: 1425-1428.

34. Rivera-Chacon DM, Alvarado-Velez M, Acevedo-Morantes CY, Singh SP Gultepe E, et al. (2013) Fibronectin and vitronectin promote human fetal osteoblast cell attachment and proliferation on nanoporous titanium surfaces. $J$ Biomed Nanotechnol 9: 1092-1097.

35. Vial D, Oliver C, Jamur MC, Pastor MV, da Silva Trindade E, et al. (2003) Alterations in granule matrix and cell surface of focal adhesion kinase-deficient mast cells. J Immunol 171: 6178-6186.

36. Yanase Y, Hide I, Mihara S, Shirai Y, Saito N, et al. (2011) A critical role of conventional protein kinase $\mathrm{C}$ in morphological changes of rodent mast cells. Immunol Cell Biol 89: 149-159. 